\title{
Sustainable Food and Local Development
}

\author{
Maria Gabriella Caruso • Maria Notarnicola
}

Published online: 15 November 2011

(C) Springer Science+Business Media, LLC 2011

The conference "Sustainable Food and Local Development" held in Castellana Grotte (Bari) on 29 April 2011 in the National Institute for Digestive Diseases and Nutrition, "Saverio de Bellis", aimed to the identification, analysis and spread of sustainable development patterns in the light of the needs of environment protection, socioeconomic development and public health preservation. In the first session of the conference, the attention focused on socioeconomic, lifestyle and physical activity determinants of the twenty-first century diseases, such as obesity, cardiovascular disease and cancer. In the second session, molecular and clinical aspects of cancer, with a look at the new frontier of green oncology, were underlined. The afternoon session stressed the ecology of food from the environmental and culinary point of view.

A healthy lifestyle should be based on scientific evidence and supports environment-friendly cultural choices, leading to the development of local economy. Another objective of this conference was to identify and put into practice the best mode of communication of this strategy for human health and wellness.

A sustainable improvement of human health and wellness requires strong alliance and partnership beyond the health arena. So, the afternoon roundtable 'Regional policies for sustainable development in agriculture, nutrition, environment and health' aimed to stimulate a dialogue between different actors (businessmen, politicians, scientists, agronomists, doctors and gastronomic tour operators, representatives of large

M. G. Caruso $(\bowtie) \cdot$ M. Notarnicola

Laboratory of Nutritional Biochemistry,

National Institute for Digestive Diseases and Nutrition,

"Saverio de Bellis",

Via Turi,

27-70013 Castellana Grotte (BA), Italy

e-mail: gabriella.caruso@irccsdebellis.it and small retailers) and people (citizens) in order to implement the knowledge for health and welfare of all the people, gained in the previous sessions of the meeting, hence the need to affirm this new philosophy through scientific meetings and debates open to the public, politicians and businessmen operating in our region, Apulia.

In the twentieth century, changes of eating habits and lifestyle, so deep and fast, have caused a significant impact on the human health. The 'gastronomic revolution' [1] has led the global increase in energy intake and the shift from mainly cereal-based diets to regimes rich in foods of animal origin and refined sugars. The changes in lifestyle and especially the progressive automation of our lives, where machines have replaced many human activities, have led to a progressive increase in body weight. The consequences on human health have witnessed the growing incidence of metabolic complications, cardiovascular disease and cancers. But the discomfort caused by these profound changes in lifestyle not only influence human diseases but also alter the balance between man and environment and the health of the planet. The growing evidence of automation in every human activity, the vast distances between places of production and consumption of foods, as well as the increasingly common use of packaged food, created using industrial processes, determine environmental pollution and high-energy consumption.

Interventions to change dietary and the lifestyles in the direction of improving human health can also affect significantly the food chain and indirectly the energy consumption and environmental pollution, protecting the health of the planet and its population. An environmentfriendly lifestyle should start right from the table, in order to protect the environment, and at the same time, to contribute to social and economic growth.

The meeting showed that a sustainable improvement of population health requires a greater understanding of its 
underlaying social, cultural, environmental and economic aspects, to support practices and policies based on ethics and knowledge, in a generational perspective. And this must be done by the local communities, in contexts of families and work places, social relations between citizens and institutions, involving and empowering those who decide and those who receive the decisions. The meeting has provided opportunities to reflect on experience and challenges of 'transferable good practice', on strategies to face new challenges to human health and on collaborations and partnerships that promote policies and practices that can improve health in a sustainable way for all the people. The roundtable provided a stimulus for discussion and possible multidisciplinary approaches to implement measures to promote a healthy diet with the conscious consumer to protect biodiversity and to promote short food chains.
Another issue, closely related to food, is promoting physical activity, with an invitation to recommend such practices in schools, families and workplaces. Examples of how local policies can increase physical activity might come from a dialogue between politicians, urban planners and citizens. It is increasingly evident that health promoters must acquire skills of opinion leaders, of facilitators of change processes and of fund raisers from local community, not only be a trainer and educator.

\section{References}

1. Bifulco M, Caruso MG. From the gastronomic revolution to the new globesity epidemic. J Am Diet Assoc. 2007;107(12):2058-60. 